\title{
Climate change and everyday life: repertoires children use to negotiate a socio-scientific issue.
} Jenny Byrne, Malin Ideland, Claes Malmberg and Marcus Grace

\begin{abstract}
There are only a few studies about how primary school students engage in socio-scientific discussions. This study aims to add to this field of research by focusing on how 9-10 year olds in Sweden and England handle climate change as a complex environmental socio-scientific issue, within the context of their own lives and in relation to society at large. It focuses on how different interpretative repertoires were used by the students in discussions to legitimise or question their everyday lifestyles. They discussed four possible options that a government might consider to help reduce carbon dioxide production. Six main repertoires were identified: Everyday life, Self-Interest, Environment, Science and Technology, Society and Justice. The Everyday life repertoire was used when students related their discussion to their everyday lifestyles. Science and technology-related solutions were offered to maintain or improve things, but these were sometimes rather unrealistic. Arguments related to environment and health frequently appeared to have a superior status compared to the others. Findings also highlighted how conflicts between the students were actually productive by bringing in several perspectives to negotiate the solutions. These primary school students were therefore able to discuss and negotiate a complex real-world socio-scientific issue. Students positioned themselves as active contributors to society, using their life experiences and limited knowledge to understand the problems that affected their everyday lives. Honing these skills within a school science community of practice could facilitate primary students’ engagement with socio-scientific issues and empower them as citizens.
\end{abstract}




\section{Introduction}

Researchers in the sociology of childhood have pointed out the importance of considering children not just as 'human becomings' (i.e. future citizens), but also as 'human beings' (i.e. citizens of today) (Johansson, 2005; Qvortrup, 1987). If children are considered as 'human becomings', there is an assumption that we just have to meet their needs for protection and fostering, but a view of children as 'human beings' also constructs them as competent citizens with rights to participate in society. From this perspective, even young children can and should be engaged as citizens. However, many researchers (e.g. Aikenhead, 2006; Freire, 1972; Pinhao \& Martins, this issue; Sadler, 2009), claim that school has failed to empower children as citizens, giving reasons such as children's lack of ability to talk about controversial issues, and teachers' lack of confidence in dealing with their questions. Hundal, Levin and Keselman (this issue) add to this debate by asserting that engaging young children in argumentation about present and future socio-scientific issues (SSIs) will create active, well-informed citizens. The mediating factors associated with discourse about SSIs have been widely recognised, mainly for secondary school (e.g. Kolstø, 2006; Levinson, 2006; Sadler, 2009; Sadler \& Zeidler, 2009). Thus, science, environmental and health issues, when treated as parts of our everyday real world experience, will inform us better than if they are just treated as knowledge belonging to specific school subjects (Roth, this issue). Faria, Freire, Baptista and Galvão (this issue) highlight the need for framing science classes in real contexts, thus enabling them to disclose and develop ideas that have meaning and significance for them beyond the classroom (Sadler, 2009).

There is a lack of research focusing on socio-scientific discussions in primary schools (Maloney \& Simon, 2006), but the evidence from the few existing studies shows that primary school students are willing and able to engage in purposeful science-based discussion (e.g. Naylor, Keogh \& Downing, 2007). Furthermore evidence shows that providing the opportunity for discussion among students can improve their reasoning and discussion skills without specialised teacher intervention 
(Solomon, 1992; Kuhn, Shaw \& Felton 1997). This study adds to the growing field of knowledge on socio-scientific discussions in primary schools by focusing on how primary school students handle a complex environmental issue of climate change. We are examining how 9 - 10 year old students use different resources in a group discussion about how to reduce carbon dioxide emissions through everyday actions, and how these discussions reflect the students' knowledge, values and everyday lives.

The overall aim of this article is to explore the nature of primary school students' talk and their use of different kinds of knowledge and personal experiences when they discuss socio-scientific issues. The research questions guiding this study are:

- What interpretative repertoires do 9-10 year old students employ when they discuss how to reduce carbon dioxide emissions?

- How are these interpretative repertoires used to understand the issue and legitimise or question everyday lifestyles?

- What role does conflict between students play in the discussion?

- What role do science and technology play in the students' discussions?

\section{Theoretical background}

Our theoretical base for exploring 9-10 year olds' talk about climate change draws on Potter and Wetherell’s (1987) analytical framework, which maintains that individuals use interpretative repertoires to construct their own versions of reality in relation to the social context, and in that way they are able to legitimise their opinions and actions. Interpretative repertoires provide students with specific resources to frame how they talk and what they can talk about. These repertoires not only reflect the individual students' opinions but they are socio-cultural resources that students share and use in a concrete manner. We explore how students' use of interpretative repertoires contributes to their negotiations in finding a solution to a SSI. In doing so we illustrate how they try to maintain 
social patterns and the status quo of their everyday lives, and attempt to establish their opinions as "truths”. It is after all, in relation to these “truths”, an individual's values, beliefs, attitudes and ideologies are constructed. Providing opportunities for students to discuss complex social issues may challenge established beliefs and opinions by raising alternative ideas, and these discussions might be helpful pre-cursors to knowledge construction.

According to Potter and Wetherell (1987) different interpretative repertoires are available to different individuals in different contexts but the range of repertoires is often restricted as a result of hegemonic discourses.We use the notion of discourse in line with Foucault (1981), as systems of thoughts comprised of ideas, attitudes, action, beliefs and practices that systematically construct the subjects and the worlds about which they speak. We employ the notion of interpretative repertoire as a temporary representation of these discourses. The repertoire can be seen as a result of a discourse filtered through students' own experiences, interests and attitudes. The repertoire is used not only to state an argument, but also to construct the individual as a certain kind of self, a discursive and temporary identity construction in their specific school context and in the context of the subject matter under discussion (Potter \& Wetherell, 1987). This discursive and temporary identity is also constructed in relation to what is seen as normal inside the discourse - both when it comes to how to live and who to be (Hall, 1996). In this paper we do not explicitly discuss identity construction, but how students construct ideas of 'normality' through employing particular repertoires.

We have intertwined this post-structuralist perspective with a socio-cultural perspective on learning, particularly in relation to science. Science learning is regarded as a discursive process that involves the appropriation and use of particular discourses, but also includes meaning-making in relation to society and to students’ own identities (Mercer, Dawes, Wegerif \& Sams, 2004). Sadler (2009) writes that we must understand school science as a community of practice where identities and 
discourses are expressed. He emphasises the importance of students having the opportunity to engage in a community where they can be central participants and express their identities, as well as learn science. Furthermore, as Hundal et al. (this issue) indicate, if the teaching is framed by issues important to the students, they become more engaged in the discussion, thus their chances of meaning-making are increased. By focusing on dialogic approaches in science education, students are given opportunities to develop more accurate scientific content knowledge and hone decisionmaking and argumentation skills (Scott, 2008). Mercer \& Littleton (2007) add that when conflict arises through critical engagement with the issue, more meaningful learning is likely compared to discussion where there is agreement between students. Similarly, Wertsch (1993) emphasised the importance of conflict for bringing out the nuances of complex issues. Letting students engage in discussions that can create conflict, diverse knowledge and experiences may facilitate more effective learning in these situations. Mercer’s concept of 'interthinking' is also useful; he defines the notion as "use of language for thinking together, for collectively making sense of experience and solving problems" (Mercer, 2000, p.1). Consideration of interthinking may help illuminate how the school context and the group invite or restrict certain repertoires and identities in the discussion.

\section{Methodology}

Participants in the study were primary school students, aged 9-10 years from Malmö, Sweden and Southampton, UK. The two cities have certain parallels. They are a similar size, traditionally working class, and with high ethnic diversity, but they also have some interesting socio-cultural and educational differences. At the time of the study the primary curriculum in England had a more cross-curricular approach in which elements of citizenship were encompassed. Sweden was moving to a more discrete subject-based curriculum but it also has a strong tradition of citizenship education and education for sustainable development. The sample of students came from diverse socio-economic backgrounds that were broadly 
representative of the populations in both cities. This background data is not used in the analysis, but mentioned here to contextualise the study. The students were engaged in group discussions about carbon dioxide reduction and climate change and this was carried out in their normal classrooms. The researchers gave a 10-minute class introduction about the issue, which included a classroom discussion with open questions about the greenhouse effect and international agreements. The aim was to set the stage for group discussions and to outline the role of carbon dioxide generation in climate change. The students, in small groups of 4-6 people, were then asked to discuss the suggestions below that a government might consider for reducing carbon dioxide production, come to an agreed position about which of the suggestions they would prefer, and provide reasons for their choice:

Suggestion 1: Parents should not be allowed to drive their children to school by car. Not even when it rains.

Suggestion 2: Air travel for family holidays should be restricted. Families will not be allowed to fly more than once a year within Europe. Another alternative is a restriction to one long distance journey outside Europe every second year.

Suggestion 3: Each family should only be allowed to own one car, and only use it for leisure purposes two days a week. This also applies to summer holidays (but we are allowed to accumulate days when it is not used).

Suggestion 4: We are only allowed to buy fruit grown in our own country, like apples, pears and plums. Oranges, clementines, bananas, grapes and melons will not be allowed since they need long distance transportation.

Students discussed these suggestions without any interference from the teacher or researcher. The suggestions were deliberately chosen as ideas that students of this age could identify 
with, and which would impact on their daily lives. Each discussion was audio-recorded and transcribed. The Swedish transcripts were translated into English by the researchers.

In England, three classes, with a total of 72 students were involved in the study. These students were distributed into 14 groups. In Sweden five classes, with a total of 99 students were involved, distributed into 25 groups. The time allowed for the group discussions was between 30 and 60 minutes. In this article we have not made a comparison between England and Sweden even though the countries have some socio-cultural and educational differences. The same repertoires were identified for both groups and they seemed to use them in a similar way, so we amalgamated the data sets to see how the students handled the issue collectively.

The analysis was carried out in three steps. Firstly, student utterances were categorised as interpretative repertoires; i.e. the discursive resources people use to construct versions of reality. One transcript was jointly read and discussed by all the researchers who then agreed the process of analysis, and the categorisation of frequent repertoires. The remaining transcripts were then analysed by the researchers individually and then sent to each other for verification. The second step was to analyse the distribution of these frequent repertoires across all the groups. In the third step, the researchers focused on how the identified repertoires were used in the discussions to legitimise opinions and negotiate/maintain social patterns. This approach gave a holistic overview of the way groups of students talked about climate change when considering alternative ways to solve the problem. 


\section{Ethical considerations}

The project followed established ethical guidelines used by the researchers' universities. All the students (and their parents/carers) gave their consent and were informed of the aim of the study. Pseudonyms have been used for the students throughout.

\section{Results}

This section starts with an overview of how we have constructed the analysis of the repertoires, and how these different repertoires were distributed in the students' discussions. We then provide results of how conflicts were employed by students as they grappled with the suggestions provided in their endeavours to find solutions, and highlight that conflict invites different kinds of repertoires compared to when student groups are in agreement. From these overall results we illustrate the key findings by presenting how two groups negotiated what they consider to be a normal lifestyle whilst trying to remain responsible citizens. We then show how conflict and the desire for solutions contributed to the complex handling of complex issues and how these 9-10 year olds acted as citizens rather than future citizens. Finally, we explore the specific role of the science and technology repertoire in relation to this active citizenship.

\section{The distribution of repertoires}

When analysing the data, the researchers used the transcripts to construct and name distinct repertoires that were employed by the students while discussing the dilemmas.. The repertoires were used to different extents according to whether students were in agreement or disagreement (conflict) with each other. These repertoires are presented in Table 1.

\section{Table 1. The repertoires employed by students}




\section{INSERT TABLE 1}

Health was identified as a further possible repertoire. Students used statements such as 'it is good for your health’. However, health was so entwined with other repertoires, particularly Science \& Technology, Society, and Everyday Life that we have chosen to regard it as an inseparable feature of those repertoires. The distribution of the six repertoires is presented in Figure 1.

INSERT FIGURE 1

Figure 1. The distribution and total number of times the repertoires were used by all the English and Swedish groups.

The most frequently used repertoire was Everyday Life, followed by Science \& Technology and Environment. We interpret the frequent use of Environment partly as a consequence of the issue being inherently environmental. The frequent use of Everyday Life reflected discussion of matters close to students' daily lives and included some kind of sacrifice from them. The use of Science and Technology is more unexpected, since the task was not presented to the students as science or part of a science class.

In the following transcript a Swedish group discuss the suggestion concerning the restricted use of private cars. The transcript shows the students' use of repertoires:

Casper: Every family should have one car! (J)

Tilde: No! (SI)

Casper: One!

Tilde: No! Two at the most! (SI) 
Miranda: But when people get divorced? (EL)

Ellen: Yes, think about when you get divorced...

Tilde: Maybe you don't work at the same place, then you must have two cars. You can't just drive the other one to work. (EL)

Casper: But do you know how much it $\left[\mathrm{CO}_{2}\right]$ uses up, if everyone has two cars? (ST)

Tilde: Two at the most! If you are rich so... (J)

Casper: So you think that if you are rich you are allowed to destroy the world for other people. Do you think so? $(J)$

Tilde: No, but...

Casper: Imagine that you were the only person with two cars. Everyone else in Malmö had just one.

Then Malmö was flooded just because the temperature increased. The Antarctic and everything...(E)

Ellen: ...Think about 2012[a the disaster movie in which the world gets flooded ]...(SO)

Casper: ...Flooding in Malmö, people would drown, it would become chaos - and everybody would blame you! Would that feel good? No, exactly! (SO)

Ellen: Think of 2012! It is not just her having two cars? (EL)

The sequence is interesting because it represents occasions of conflict or challenge between the students, and exemplifies the use of different repertoires as the students critically engaged with the debate. In fact, all six repertoires are represented. Tilde used Self-interest to argue for more than one car per family and Ellen supported her, using Everyday Life to illustrate a common situation that Tilde then endorsed. But Casper disagreed and used Justice to claim that rich people don’t have the prerogative to destroy the world. Casper countered Tilde by using Science \& Technology to explain about increased carbon emissions. 
The quote above illustrates a conflict. The range of repertoires students from all groups used when they were involved in conflicts is presented in Figure 2.

INSERT FIGURE 2

Figure 2. The distribution of the repertoires from all the English and Swedish groups when in conflict.

The proportionally high frequencies of Self-interest can be noted in arguments about wishes to retain one’s normal expectations and maintain the status quo (e.g. travelling abroad two or three times a year), or to have a luxurious lifestyle (e.g. eating exotic fruits). The Justice repertoire was used to argue for the right for everyone to have the same opportunity to travel, or to visit family that live abroad, or the right to go to school by car. This result highlights the importance of allowing students to relate discussions to their everyday lives and own interests. Conflicts were productive for students' meaning-making with regard to their attitudes about their lifestyles and their beliefs about fairness and yet needing to find a solution to the problem. The alternative to conflict is agreement to support a solution. The range of repertoires students used when they were involved in non-conflicting negotiation to come to a solution is presented in Figure 3.

\section{INSERT FIGURE 3}

Figure 3. The distribution of the repertoires all English and Swedish groups used in nonconflicting negotiation to come to a solution.

The distribution of repertoires changed when students were in negotiation to support a solution. Science \& Technology was used more frequently to find the answer to a problem by referring to new technologies (e.g. in solar-powered airplanes). But students also discussed the importance of finding political agreements, and in these instances Society repertoires were 
used. For example, introducing a 'fruit-week' to solve the problem of importing foreign fruit, or to reduce the price of train tickets to encourage travel by train rather than by car or aeroplane. In line with Reeve, Bricker \& Bell (this issue) the students considered several perspectives, bringing in many different experiences and types of knowledge. Where there was conflict or agreement in working towards a solution, the students employed a range of repertoires and nuanced arguments and this may have raised their awareness of the complexity of the SSI.

\section{Use of repertoires}

In this section we explore more closely how the repertoires were used in negotiating the SSI as well as their own lifestyles and identities. We have selected one English group and one Swedish group to provide a more in-depth illustration of how the repertoires were used to legitimise opinions and maintain normal everyday social patterns. These two groups represent, in different ways, how presenting a problem can be a driving force for developing argumentation that incorporates many perspectives on an issue.

The Swedish group consists of two boys (Olof and William) and two girls (Hanna and Nova) and was selected for three particular reasons. A) They remained engaged in discussion for a long time (almost an hour). B) There was a considerable amount of disagreement in the group. C) They employed many different repertoires, especially when they tried to find a societal solution to the suggestion of not eating foreign fruit. Hence this group is an example of how conflicts can be productive in discussion of SSIs.

The English group consists of two boys (Alan and Wayne) and four girls (Leah, Jane, Sarah and Sophie) and was chosen for the following three reasons: A) All the students had a voice in the discussion, and they discussed animatedly for a relatively long time (about 40 minutes), B) They didn’t agree with any of the proposals but, unlike their Swedish counterparts, they tended to agree 
with one another, and C) They also employed a wide range of repertoires to support their arguments, and conflict occurred when they began to explore their reasons for rejecting the proposals. This group is therefore an example of how initial consensus can be productive for developing a socio-scientific discussion.

\section{Construction of normality}

The students were operating from a variety of personal perspectives as they dealt with the suggestions to reduce carbon dioxide. They could see how these suggestions could change their lives, but not always in a desirable direction:

William: What do you think about the first suggestion? ...I think it was quite good.

Nova: Well, sort of...cycling with an umbrella can be a little strange, but you can walk. [EL]

Hanna: If it is pouring with rain it can be a little weird. [EL]

Olof: Yes, I think it is a little weird if you live far away from school, because then you can't go to school by yourself. [J]

Nova: What? Don't you cycle by yourself? [EL]

Olof: I still think it's worth it because you then help the environment... [E]

Nova: Yes!

William: ... so then it is probably still quite worth it. [E]

Hanna: ... It's a little weird... [EL]

Nova: I go to school every day, whether it rains or not [EL]

This suggestion of walking (or not) to school is grounded in the students' everyday lives, and it is therefore not surprising that the Everyday Life repertoire and the Self-interest repertoire were used. But what is striking is how negotiation of what sacrifices they were willing to make also included the negotiation of normal behaviour and normal opinions. As the students discussed the suggestions they were constructing and negotiating normality. For example, Hanna’s reference to what she considered as 'weird'. William, on the other hand considered the normal thing to do is to think of 
the environment. He took the role of an environmental advocate and employed that repertoire to legitimise normal behaviours. But this doesn't necessarily mean that this repertoire is "better”, or at a higher level of thinking. William is probably already walking to school, and therefore this is not a problem for him. In a similar manner, Nova used the Everyday Life repertoire to confirm her normal behaviour by suggesting small alterations to regular routines. The Environment repertoire was however used to legitimise a normal social pattern. The same pattern emerged when the group discussed family cars:

Hanna: My mother always works on Monday, and she has to drive there, and sometimes it can get a bit late for me to get to training. [EL \& SI]

William: But imagine this Hanna ... You can use the car twice a week during leisure time. You have soccer two days a week, so then you can go to football by car, and then you cycle to school... [EL] Nova: Or walk. [EL]

William: ... and on Saturdays you then simply cycle to football. [EL]

Hanna: Can I just say one thing? I just don't want to do that. [SI]

William: ... But are you thinking of the environment now? [E]

Olof: ... I think it's bad [William's idea]... [SI]

Nova: William and Hanna, can I just say one thing. This [restriction] was during leisure time, it is not for adults at work, right? And when your mum works it is not leisure time. [EL] Hanna: Oh, OK ...

Here William used the Everyday Life repertoire to negotiate with Hanna. Since they were now dealing with another good thing in their lives - their training and health - it was not deemed socially acceptable to say that Hanna shouldn't go to football training, 'because of the environment'. Another argument was needed and the negotiating took on a new shape. Car driving was legitimised by the comment 'it is not leisure time', and normal life could be maintained even if some were unwilling to accept the suggestion. 
The English group did not agree with any of the suggestions, but they were engaged in the issue, not least because they considered the suggestions would adversely affect their everyday lives. The discussion was very much a way to justify their positions against the anticipated changes inherent in the suggestions, and retain a normal life:

Jane: (discussing suggestion 1) ... It's dangerous if it's icy and if you fall over in the snow then it's dangerous, and it's not very nice to walk in the snow but it's not really nice to drive in the snow either because there could be a crash or something. [EL]

Wayne: Well I don't actually agree with any of the suggestions because, like suggestion 1, for parents driving to school ... Well, Winchester is a very big town and I live here and the station is here and it would be more money for my Mum to drive from here (my house) to here (the station) than it would to drive me to school and it would be more of the carbon, carbon dioxide. So I don't agree with any of them. [EL]

Sarah: My Dad has to drive a car every single day to work and has to use a car to get building materials for houses and stuff like that... And my Dad has to be working somewhere, and my Mum has to go somewhere else...shopping or something and then we have to have two cars one for my Dad and one for my Mum. [EL]

The students' negotiations not only reflect how their normal life could be jeopardised, but also include their parents. Many groups referred to the effect on their parents' lives (getting to work, etc.), which further legitimised the students’ position because this normality is not negotiable, and probably reflected a way of talking at home. There was no mention of parents going to work by bus or bike in their conversations, suggesting that they could not imagine an alternative for their parents. The parents' everyday life was present in the discussions in other ways. For example, when Sophie referred to her father: ...well my father is very hyperactive and has to have these tablets that are made from some fruit that comes from abroad and that they can't grow in this country. The 
forbidding of importing fruits from abroad was negotiated here with a quite surprising argument. But this Everyday Life repertoire, underpinned by a health argument, even if it may be spurious, was very hard to oppose. Health, as a hybrid discursive formation (Pinahao \& Martins, this issue) is a useful argument in many fields of society; it can legitimise everything from use of animals and embryos in biomedical research, to school curricula and diets. Foucault (1982) referred to health in terms of salvation, and this discourse is so deeply rooted in western culture, that even the Environment repertoire cannot counter the 'magical' status of health in discussions. Health appears to be a superior, all-embracing repertoire and is therefore a very useful negotiating tool. The powerfulness of the health argument is also illustrated when other students discussed fruit. For example, Viktoria, in one of the other Swedish groups used the health argument to legitimise imported fruit: “Bananas are healthy. Clementines are healthy. Melons are healthy”. On the other hand, Ian in another Swedish group used the same argument to oppose import of fruit: “Because you can eat apples, pears and plums here, which we have here, because they are healthy. They are healthier than melons and such things”.

Certain attitudes are often instilled in children as they grow up, such as 'save the planet', 'stay healthy' and 'being fair'. The Justice repertoire of being fair was also useful in the students' argumentation to maintain normal life, as well as reflecting on habitual events. Here William, the environmental advocate, challenged normal life expectations:

William: You must agree that we have become so used to this luxury of being able to go where you want. $[J]$

Hanna: I like to go to Thailand. [SI]

William: But to go once a year ... considering how much airplanes really emit. [E] Olof: Well, that's a point.

William: Yes, but you might as well take the train to Are, then take the train to ... [EL] Hanna: I can't go by train to Thailand. I think that's weird... [SI] 
Hanna thought that it was "weird" to not be able to go to Thailand every year. What was regarded as ‘justice’ and a normal way of living differed between different schools as some children had different socio-economic standards and lifestyle expectations. Even though these differences are not considered here, what is important to note is the use of the Justice repertoire in generally arguing for the maintenance of normality.

Furthermore, the students engaged in the issue on a societal level. The English group had quite well-informed conversations about economics and trading in relation to the suggestion about forbidding imported fruit. This extract starts with the UK government's well-known 'five pieces of fruit a day’ health argument, and was situated in a societal context and moved on to a broader societal/economic discussion:

Alan: ...people say to you you've got to have your 5 a day. If they're going to stop sending fruit over then we're hardly going to have any fruit in the supermarket, and then you won't be able to eat your 5 a day and... So, what's the point of saying 'oh have your 5 a day' and then they're stopping it. [SO] Jane: ....it's not only because of the fruit but the other things because we've got lots of stuff that's made in China and sent over here and that would be stopped so you wouldn't have that much stuff to sell, and we wouldn't get enough money. So I think aeroplanes should still send stuff but not so many people but still a lot of fruit and stuff because it just helps us with the money and everything. [SO]

Alan: ... I also agree with Jane, because we need aeroplanes to bring us things to use. Some of our toys like for the boys Star Wars stuff and our mobiles are made in China, and if we hadn't those things to play with.... [SO, EL]

Wayne: Well, I have a proper England football kit, and it's made in a foreign country. So if we didn't have football kits, we wouldn't ever be able to play football because we wouldn't have the 
kits [SI, EL]. I agree with Jane because lots of stuff is made in China, a lot of things are made abroad [SO]. So well, I think we should have it. [SI]

Leah: I was watching this film and children had no fun stuff, and we'd soon be like that if they don't bring us any toys and we'd just be doing nothing [SI]. All the work books would be already coloured in. So we'll have nothing to do... So it would be better if they actually bring us stuff from aeroplanes and things like that. [SO]

The group agreed to disagree about not having foreign fruit, there was no conflict and they maintained their consensus of opinion by using a variety of repertoires. The main argument was based upon 'five a day', an embedded health education message from the UK government, recommending that everyone should eat five portions of fruit or vegetables each day to stay healthy (NHS, 2012). The discussion then broadened to encompass the import of other goods. Here, Selfinterest repertoires were coupled with Science \& Technology, Everyday Life and Society repertoires to argue against the unwelcome changes that the students perceived resulting from the suggestion to stop fruit imports.

\section{Complex handling of complex issues}

The Swedish group used many repertoires to handle the conflict around the issue and agreed upon an unexpected solution. In these discussions both groups of students used many strategies to make these complex issues possible to manage through discursive acts. Small-scale activities like walking to school, turning off lights and recycling are examples of how students (and adults) talk about handling the climate change issue. Students also brought in new or future technology as solutions, like sun-powered flights and electric cars. These innovative suggestions can be related to the public debate (e.g. fusion power or offsetting carbon dioxide emissions on flights). Offering students opportunities to discuss complex SSIs means that classroom discussions incorporate familiar societal arguments and discourses as students sought to make meaning of the complexity of the 
problems through the use of their interpretative repertoires (Potter \& Wetherell, 1987). It is not surprising that the students made use of many different arguments available to them. This has implications for any subsequent teaching that must ensure a clear focus on supporting the students' understanding of the rationale underpinning the arguments in order for them to develop accurate knowledge.

The Swedish group used and mixed repertoires to provide one solution - an annual foreign 'fruit week' - to the suggestion about not importing fruit:

Olof: I can't imagine life without melons [SI]

Hanna: ... Well, I like melons too, but we can grow apples here [SI \& EL]

William: That's good ... if you think about the environment [E]

Nova: We take care of our apples we have in the summer ....we bake apple pie, and we take our own apples from the garden.... we can grow these. And, we can buy a melon once in a while. It might be possible to plant your own grapes, and make lots like that, my neighbours did and it worked. [EL]

Olof: I think we should eat melon once a year or something, just to make us feel that it's a luxury, because it needs so much gasoline. [E]

Hanna:... If all the things that we get from somewhere; if they were provided only perhaps every other month or something like that. [SO]

Nova: ... If you had that fruit-week, who would decide when it was? would you decide it with your family? [SO]

William: Well, once a year you decide [SO]

Olof: But it is really difficult. How can you check it out and keep track of people so that they do not have fruit weeks all year round? Like...every other week ... [SO]

Nova: But Olof, you and your family keep track of your own fruit weeks [SO]

Olof: Yes, but imagine that there is another family who ... [SO \& J] 
William: Are shopping 'sneakily', that's right. [SO \& J]

William: At least here we agree but you two girls refuse to choose this suggestion

Nova: Yes, but we think it is good

Hanna: I think it's a bit [weird].

The discussion continued about how to arrange the fruit week, and how to control people's purchase of foreign fruits. The students used a Society repertoire while discussing a political solution to the problem by suggesting that the Environment Minister should oversee the fruit week. All six repertoires were used, and it started with a conflict from Olof in terms of Self-interest when he stated that he could not 'imagine life without melons'. At the beginning the students appeared to find the problem insurmountable, but they wrestled with it in a discursive manner until they constructed a solution on their own. The solution (the fruit week) actually appeared early in the discussion, but they could also foresee problems with introducing the fruit week - both for themselves and for the society. However, the students invested whole-heartedly in solving the problem and used the whole range of repertoires. They also mixed the repertoires in new ways, offering societal solutions (annual fruit week) to a problem that might be thought of as an individual choice. Instead of trying to maintain normality, the students discussed ways of changing the social order, and in doing so they provided an interdiscursive mix, that has the potential to become a force to change social patterns (cf Fairclough, 1992, Wertsch, 1993). Furthermore, the students did not relate to the discourse order of the school by trying to find the right answer as students usually do in school (Ideland \& Malmberg, 2012) or trying to please the teacher, or the researchers. They saw themselves as experts, and as responsible citizens rather than students, and they produced (rather than reproduced) knowledge by suggesting a new idea at a political and societal level. 


\section{But what about science and technology?}

Sadler (2009), Hundal et al. (this issue) and Faria et al. (this issue) have emphasised the importance of engaging students in a science community framed by issues important to the students themselves, where they can be central participants and express their identities as well as learn science. Judging by the intensity of on-task discussion, this SSI was important to the students, and they were keen to find solutions. Indeed, the discussions showed little sign of ecological cynicism, hopelessness or ‘environmental depression’ of the kind described by Zeyer and Roth (2013) who revealed interpretive repertoires underpinning post-ecological discourse among teenagers. It would appear that these younger children tended to have a more positive outlook.

The Science \& Technology repertoire was mainly used by the students to agree on a solution about how to reduce $\mathrm{CO}_{2}$ emission, whilst maintaining their normal lifestyles. Although they had plenty of technological solutions such as electric cars, solar cell aeroplanes and alternative energy sources, these were sometime fanciful and not based on scientific knowledge. This is evident in Jane's comment below:

Jane: ...if you wanted to drive [your children] off to this nice little place for a birthday party [EL]...What if you made some kind of strange machine that ran on pollution and it would be using energy that we're trying to get rid of and you'd still have the comfort of your car and you'd be getting rid of the gases [ST]

Jane used the Science \& Technology repertoire as a kind of 'magic bullet'. However, this was not challenged by other students as it forms part of their 'folk science discourse' (Zeyer and Roth, 2013) and was accepted as such; thus the possible technological solution helped the students avoid conflict and maintain their lifestyle. Technological solutions to solve problems with energy production are also prevalent in the public debate, where ideas about nuclear fusion, clean coal and solar panels in deserts are common, and this is an example of how students brought public debate 
discourses into their discussions. Of course, children of this age are not alone in believing in farfetched solutions; even prominent politicians have been known to rely on over-ambitious ideas, Ronald Reagan's prematurely ambitious Strategic Defense ('Star Wars') Initiative being a famous example (Nolan, 2002). However, in the following excerpt Swedish students introduced science into the conversation as they discussed the impact of speed on the amount of pollution cars produce, although they did not agree about whether or not speed restrictions are better for the environment: Mostafa: ... The slower you drive, the better it will be for the environment Loke: But you drive the same distance, and so it will be the same amount of fuel, it is just that you drive slowly and you let out less per minute.

Mostafa: Well if someone is going to work at quarter past seven, and he must be there at eight o'clock, he may have to drive fast. But if you think about the environment, he should drive slower and start earlier. You'll arrive at the same time. So you will not be late to work, even if you drive slower.

Loke: But it is still the same distance! The exhaust gases will still come out. And it comes out just as much. It's just that they run slower and it comes out less per minute ... When you drive fast it might come out more, but if you go slow it will take longer time so it will be the same pollution. [whole excerpt: ST]

Mostafa is of course generally correct although the relationship between speed and fuel consumption is not entirely linear. This represents an occasion when there is a conflict within the science discourse, and scientific reasoning, albeit somewhat erroneously, was used to try to develop understanding. At this point, it would be useful for the teacher to intervene and provide an opportunity to help them reason more effectively resulting in more meaningful learning (Scott, 2008). Whilst the physics is complex for primary aged children a discussion of the factors, such as the speed of the vehicle, air resistance and the road surface that can affect fuel consumption could be initiated by the teacher. Positive epistemological outcomes are important, but of equal value is 
the students' use of knowledge when solving a problem and making meaning of the world (Bereiter, 2002). That said, it is important that students’ ability to debate knowledgeably about SSIs is developed, as this has implications for their engagement and role as full participants in society now and in the future (Johansson, 2005).

However, the most common use of the Science \& Technology repertoire was to offer a sciencerelated solution to the climate change dilemma of protecting the environment while maintaining one’s own lifestyle, which inevitably connects it with the Self-interest repertoire. Science and technology appears to be something that cannot be questioned, and the repertoire was characterized by providing 'the truth'. Similarly the Environment and Justice repertoires, as well as Health have the same character of being related to the 'truth'. It would appear that students did not think it was possible to be opposed to science/technology or justice or environment arguments, and therefore the potential for conflict or negotiation between the group members was not possible in these discourses. These uncontested repertoires, that are frequently part of the public discourse about science, suggest that students have firmly held beliefs about particular ideas that are difficult to contradict because they form part of their folk science discourse (Zeyer and Roth, 2013). This may lead to less fruitful discussions (Mercer \& Littleton, 2007) and thus has implications for learning. Therefore the goal of working with SSIs should involve the students in critical thinking and argumentation, in line with Ratcliffe and Grace (2003) who recommend inviting students to consider not only stated 'truths', but also everyday life and societal processes. Focusing on either the 'socio' or the 'scientific' part of the issue may result in the discussion taking different shapes. If the focus is social, the science and technology might not be explicit, resulting in the loss of opportunities to develop scientific understanding. On the other hand, if the focus is on science, with authoritative claims to truth, there might be limited opportunity for developing reasoning skills. Situativity theory indicates that all learning is situated, and the learning environment has an important bearing on students’ cognition (Bransford, Brown, \& Cocking, 1999). Learning is 
distributed across a range of learning environments (Barab \& Plucker, 2002) as students’ learning experiences differ according to their surroundings, not only in terms of how dynamic or impoverished these are, or whether students are in a formal or informal learning situation, but the learning will also be different depending on whether students are in a science-related lesson or a citizenship-related lesson, with a teaching emphasis on science and society respectively.

\section{Concluding discussion}

This study makes both empirical and methodological contributions to the field. We hope that the interpretative repertoires identified will be of value to other teachers and researchers as an analytical tool for evaluating students’ discussion. Our approach did not limit students to a 'scientific' discourse and this freedom resulted in complex and interesting discussions that included a wide range of repertoires. Students often developed their arguments based on concrete everyday life experiences, which we refer to as 'everyday' or 'normal'. These discussions highlighted their cultural norms and values and in doing so they began to express their identities within the context of carbon dioxide reduction and climate change - for example as an environmental advocate. It would appear that conflict rather than consensus provided richer and more productive discussions.

Interpretive repertoires have been used to good effect by other researchers (e.g. Zeyer \& Roth, 2013) to analyse student discourse, but here we have enlisted repertoires as a novel methodological approach to analysing primary student discourse, and have shown that they employ a wide range. Some, such as the Environment repertoire appear to be non-negotiable due to their superior status in the minds of the students, whilst others such as health pervade several repertoires and thus are regarded as being superordinate to other repertoires. When students discuss this particular socio-scientific issue the study found that although these primary students' understanding and use of scientific ideas was limited, they were keen to 
seek technological solutions to the problem. Whilst we acknowledge that accurate subject knowledge is an important epistemological goal we consider students' use of available knowledge to frame their arguments is an important pre-cursor to facilitating new understanding (Bereiter, 2002). In addition, articulating and discussing ideas can improve students' competence with regard to decision making and critical thinking skills and give them greater autonomy over their own learning (Wesselink, Dekker-Groen, Biemans \& Mulder, 2010). These skills are regarded as an essential component of the suite of attributes required for learners in the $21^{\text {st }}$ century (Claxton, 2008).

The students in this study were willing and able to engage in the socio-scientific discourse. They exhibited the ability to reason through their ideas and were given the agency to legitimise their position and construct their identities (Pinhao \& Martins, this issue). As argued by Roth (this issue) it is often the structure of schools (e.g. the compartmentalisation of subjects) that constitutes the problem of why science education is perceived as having so little to do with everyday life issues. Relevant social and cultural aspects of students’ personal lives and experiences were highly evident in discussions (Mercer \& Littleton, 2007). In line with Sadler's (2009) notion of positioning classrooms as communities of practice, where students can negotiate as engaged citizens rather than professional scientists, these students grappled with the problem they had been set using a wide range of interpretative repertoires. The students identified with the issue in different ways, which created tensions and dilemmas that some found problematic to resolve, but these conflicts assisted the development of a socio-scientific discourse. As the students talked, they positioned themselves as active contributors to society, using (sometimes inaccurate) scientific and technological ideas, among others, to understand the problems that affected their lives. In this sense it is possible to see them as legitimate participants in a socio-scientific discourse. 
The students expressed the need to reduce $\mathrm{CO}_{2}$ emissions as a result of prior knowledge and from the researchers' introduction to the activity. However, when the need for change was introduced in the discussions, the wish to maintain a normal lifestyle was often a first priority. Using different repertoires, they created solutions that made it possible to change social patterns while also maintaining normal lifestyles and responsibilities. These discussions indicate that 9-10 year olds can use available repertoires and work together on problem-solving tasks about this SSI. All the students were engaged in the discussions, some quite passionately, to a degree of sophistication possibly unexpected by many teachers and educators. It would appear that young students are quite capable of applying a variety of repertoires to sustain an argument. By interacting with one another through dialogue, the students were given opportunities to use their decision-making and argumentation skills, illustrating the usefulness of this approach as a valuable pedagogical practice. However, the student groups adopted two very different approaches to decision making, some centering around conflict and some around agreement. Merely introducing SSIs into the curriculum will not necessarily facilitate critical or transformative thinking when it comes to issues about environment and health (c.f. Pinhao \& Martins, this issue) but providing opportunities for discussion can empower them as citizens. This coupled with the mobilization of scientific and other knowledge and competencies can help students make sense of new social issues as they arise (Faria et al., this issue). If we consider students as 'human beings' who can engage in SSIs seriously we must encourage changes to pedagogical practice that provide more opportunities for primary school students to engage in discussion and debate. Furthermore we consider that training students and teachers to manage these debates, and promote rather than avoid conflicts, can lead to more fruitful and productive learning (Mercer \& Littleton, 2001; Hundal et al, this issue). To support such changes we need to help teachers and education policy-makers to re-conceptualise science teaching goals to include discussion of SSIs which draws on students' own experiences as emerging scientifically literate citizens. 


\section{References}

Aikenhead, G. (2006). Science Education for Everyday Life. New York: Teachers College Press.

Barab, S. A., \& Plucker, J. A. (2002). Smart people or smart contexts? Cognition, ability, and talent development in an age of situated approaches to knowing and knowing. Educational Psychologist, 37, 165-182.

Bereiter, C. (2002) Education and mind in the knowledge age. Mahwah: Lawrence Erlbaum Associates, Inc.

Bransford, J. D., Brown, A. L., \& Cocking, R. R. (1999). How people learn: Brain, mind, experience, and school. Washington, DC: National Academy.

Claxton, G. (2008). What's the point of school? Rediscovering the heart of education. Oxford: Oneworld.

Faria, C., Freire, S., Baptista, M. \& Galvão, C. (this issue). The construction of a reasoned explanation of a health phenomenon: an analysis of competencies mobilized. International Journal of Science Education.

Fairclough, N. (1992). Discourse and social change. Cambridge: Polity Press.

Freire, P. (1972). Pedagogy of the Oppressed. Harmondsworth: Penguin.

Foucault, M. (1981). The order of discourse. In: R. Young (ed): Untying the text. A poststructuralist reader. (p 52-64). London: Routledge.

Foucault, M. (1982). Afterword. The subject and the power. In H. Dreyfus \& P. Rabinow (eds) Michel Foucault. Beyond structuralism and hermeneutics. Hertfordshire: Harvester Wheatsheaf. Grooms, J. \& Sampson, V. (this issue). Comparing the effectiveness of verification and inquiry laboratories in supporting undergraduate science students in constructing arguments around socioscientific issues. International Journal of Science Education. 
Hall, S. (1996) Introduction: Who needs identity? I: Hall, S \& du Gay, P (eds): Questions of cultural identity. London: Sage.

Hundal, S., Levin, D. M. \& Keselman, A. (this issue). Lessons of researcher-teacher co-design of an environmental health afterschool club curriculum. International Journal of Science Education. Ideland, M. \& Malmberg, C. (2012). Body talk. Student’s identity construction while discussing a Socio-scientific issue. Cultural studies of science education, 7 (2), p 279 - 305.

Johansson, B. (2005). Barn i konsumtionssamhället. Stockholm: Norstedts.

Kolstø, S.D. (2006). Patterns in students’ argumentation confronted with a risk-focused socioscientific issue. International Journal of Science Education, 28(14), p 1689 - 1716.

Kuhn, D., Shaw, V., \& Felton, M. (1997). Effects of dyadic interaction on argumentative reasoning. Cognition and Instruction, 15(3), p 287-315.

Levinson, R. (2006). Towards a theoretical framework for teaching controversial socio-scientific issues. International Journal of Science Education, 28(10), p 1201 - 1224.

Maloney, J. \& Simon, S. (2006). Mapping children’s discussions of evidence in science to assess collaboration and argumentation. International Journal of Science Education 28 (5), p 1817-1841. Mercer, N. (2000). Words and Minds: How We Use Language to Think Together. London: Routledge.

Mercer, N., Dawes, R., Wegerif, R. \& Sams, C. (2004). Reasoning as a scientist: ways of helping children to use language to learn science. British Educational Research Journal, 30 (3), p 367-385. Mercer, N. \& Littleton, K. (2007). Dialogue and the development of children's thinking: a sociocultural approach. London: Routledge.

Naylor S., Keogh B. \& Downing, B. (2007). Argumentation and primary science. Research in Science Education, 37, p 17-39.

NHS (2012). 5 A Day. National Health Service, UK. http://www.nhs.uk/livewell/5aday/Pages/5ADAYhome.aspx 
Nolan, C.J.(Ed.) (2002) The Greenwood Encyclopedia of International Relations (Volume 4), Westport US: Greenwood Press

Pinhao, F.L. \& Martins, I. (this issue) Relationships between health and environment in a Brazilian science textbook: a discursive analysis. International Journal of Science Education.

Potter, J. \& Wetherell, M. (1987). Discourse and Social Psychology. London: Sage.

Qvortrup, J. (1987). The sociology of childhood. Barndomsprojektet 2/87. University centre of South Jutland.

Ratcliffe, M. \& Grace, M. (2003). Science Education for Citizenship. Maidenhead: Open University Press.

Roth, W.-M. (this issue). Personal Health - Personalized Science: A New Driver for Science Education? International Journal of Science Education.

Reeve, Bricker \& Bell (this issue) "She has to drink blood of the snake”:

Culture and prior knowledge in science|health education. International Journal of Science Education.

Sadler, T.D. (2009). Situated learning in science education: socio-scientific issues as contexts for practice. Studies in Science Education, 45(1), p 1-42.

Sadler, T.D. \& Zeidler, D.L. (2009). Scientific literacy, PISA, and socioscientific discourse: Assessment for progressive aims of science education. Journal of Research in Science Teaching, 46(8), p 909-921.

Scott, P. (2008). Talking a way to understanding in science classrooms. In. Mercer. N. and Hodgkinson, S. (eds) Exploratory talk in school. London: Sage, p 17- 36.

Solomon, J. (1992). The classroom discussion of science-based social issues presented on television: Knowledge, attitudes and values. International Journal of Science Education, 14(4), p 431-444. 
Wertsch, J.V. (1993). Voices of the mind. A sociocultural approach to mediated action. Cambridge, Mass: Harvard University Press.

Wesselink,R., Dekker-Groen, A.M., Biemans, H.J.A. \& Mulder. M. (2010). Using an instrument to analyse competence-based study programmes: experiences of teachers in Dutch vocational education and training. Journal of Curriculum Studies, 42, 6, 813-829.

Zeyer, A. \& Roth, W-M (2013) Post-ecological discourse in the making, Public Understanding of Science, 22(1), 33-48 